\title{
Students' Progress throughout Examination Process as a Markov Chain
}

\author{
Robert Hlavatý ${ }^{1} \&$ Ludmila Dömeová ${ }^{1}$ \\ ${ }^{1}$ Czech University of Life Sciences, Prague, Czech Republic \\ Correspondence: Robert Hlavatý, Department of Systems Engineering, Faculty of Economics, Czech University \\ of Life Sciences, Kamýcká 129, 16521 Prague, Czech Republic. E-mail: hlavaty85@gmail.com
}

$\begin{array}{lc}\text { Received: August 6, } 2014 & \text { Accepted: September 26, } 2014 \quad \text { Online Published: November 26, } 2014 \\ \text { doi:10.5539/ies.v7n12p20 } & \text { URL: http://dx.doi.org/10.5539/ies.v7n12p20 }\end{array}$

\begin{abstract}
The paper is focused on students of Mathematical methods in economics at the Czech university of life sciences (CULS) in Prague. The idea is to create a model of students' progress throughout the whole course using the Markov chain approach. Each student has to go through various stages of the course requirements where his success depends on the completion of the previous duties. It makes the whole process ideal for usage of Markov chain theory in practice. We show how students' achievements during the semester affect the final result of the exam in terms of the final grade. The final grade can be understood as an absorbing state of a Markov chain that is terminal and cannot be transitioned from. With the help of Markov chains, the probability of success at the end of the course is shown regarding the students' behaviour and diligence during the course. This helps to identify weak or critical stages of the entire course and also supplies the planning of time capacity that will be needed to examine all students in the end. The mathematical model is constructed and consequently used in the case study at the second half of the paper.
\end{abstract}

Keywords: examination, absorbing Markov chain, probability of success, teaching of quantitative methods

\section{Introduction}

The evaluation of students' progress is a very important part of any educational system. Making the decision to let a student pass or fail is difficult especially if the teacher is supposed to decide only by the final exam results. The performance of the student can be influenced by many factors and the teacher has limited time to assess the acquired knowledge and other required skills. The difficulty of the decision is compounded by the fact that students need time to learn, so mistakes are to be expected (Scanlan et al., 2001). Failing a student is stressful both for the student and for the teacher (DeBrew \& Lewallen, 2014).

To make a final grade decision is even more complicated if the teacher does not know the student personally and does not have enough information about the student's progress during the course. To support the decision making process at the final exam, the partial evaluation during the semester can be introduced. This was the case of the investigated course with about a thousand of students and ten teachers. Passing the partial tests during the semester enables the students to move forward to the exam. To get to the face to face communication with the examiner suppose passing the written examination test.

There are three attempts for passing the final exam with some time for study in between the attempts (usually all the attempts must be finished in 5 weeks) in order to improve the results (to pass). The results of these attempts can be also taken as a partial evaluation serving as a feedback for the student. The whole process is described further in the Method section.

The question is how the partial grades influence the final grade. Both the partial evaluation and the final exam is time demanding hence it is important to evaluate each stage of the students' evaluation. The goal is to define the role and significance of all the evaluation stages and think over some reduction or enhancement. The mathematical model based on Markov chain is possible to apply because each student must finish several phases before getting the final grade.

\subsection{Background}

The final grades are often used as a measure of transmission of knowledge in a course, for evaluation of the teachers, the university, and the curricula. Assessment can be a powerful force for supporting learning and a mechanism for individual empowerment (Broadfoot \& Black, 2004). The availability and accuracy of 
information on academic performance affects both the design of the educational system and the functioning of the labour market (Betts \& Grogger, 2003). Recently, there has been growing attention to academic standards related to the connection of students' entry levels and their assessment outcomes (van de Watering \& van der Rijt, 2006)

It is generally supposed that the final grade is a measure of the students learning in the particular course but there are many more influential factors.

The reality in addition to the absence of an objective measure of student learning further faces a number of difficulties regarding empirical methodology (Beleche et al., 2012). The grades are never totally objective. Their variation arises from three sources: the student, the teacher, and "nature", which reflects random and unmeasured factors (Grant, 2007).

The teachers vary considerably in their grading standards (Figlio \& Lucas, 2004). The high grading standards may help some students at the expense of others (Betts \& Grogger, 2000).The students benefit academically from higher grading standards while the high-ability students benefit more than low-ability students (Figlio \& Lucas, 2004). The higher graduation standards lead to relatively increased dropout rates and affect decisions to remain in school (Dean et al., 2001). The dropout rates are serious issue in many western countries while the attention has been shifted from the demographic and family factors more to the psychological and behaviour factors of the students (De Witte et al., 2013).

The assessment and other skills of the teacher play an important role. Kyriakides et al. (2009) stated that the teacher's behaviour is dependent on his or her beliefs and knowledge and interpersonal competences. Grades may vary across teachers in the same institution because some instructors are more willing to withstand the complaints (Stratton, Myers, \& King, 1994). The grade inflation results from the desire of both instructors and students to be "nice" and with the academia's progressive loss of autonomy (Oleinik, 2009).

On the student's side, grades may vary due to differences in the willingness to trade off leisure for study or in the ability to learn a subject (Grant, 2007). The student's background (i.e. age, gender, father's and mother's education level, the social status of father's job, the social status of mother's job and the economic situation of the family) has significant effects on student's achievement but the strongest effect has the prior knowledge (Christoforidou et al., 2014). The self-estimation is not necessarily in line with the prior knowledge. Dochy et al. (1999) stated that the more prior knowledge a student has, the more he tends to underestimate his performance. The relationships of the achievement motivation (having three types of achievement goals, i.e. mastery goals, performance goals and social goals) and the achievements (particular learning in a particular setting which is defined by examination grades) are positive and significant with remarkable gender differences (Awan et al., 2011).

One of the unmeasured factors is often the item difficulty. An assessment can contain some easy items as well as some difficult items, but the overall difficulty of the assessment should be adjusted to the level of the student population taking the assessment. An assessment should have a certain level of difficulty, enabling an average student to pass. Average students can be defined as those who are generally sufficiently prepared for participation in the classes and have confidence in their own capacities to study for the assessment (van de Watering \& van der Rijt, 2006).

The predictive power of partial evaluation has not been clearly determined. By Hamid et al. (2013), a positive self-esteem, proactive coping, and mathematics anxiety are predictors of good results in mathematics. Grant (2007) shows that performance in a previous class has no predictive power in the following class. By Beleche et al. (2012), the grade received on the final exam is superior to the grade in the course.

The utilization of partial testing in the teaching-learning process involves breaking up the subject matter content into smaller hierarchical units for instruction; specifying objectives for each units; designing and administration of validated formative test; offering a group based remediation in areas where students are deficient before moving to another units and then administration of summative test on completion of all units (Ajogbeje et al., 2013). Ajogbeje (2010, in Ajogbeje et al., 2013) opined that the breaking up of subject or course into small units enables students to adequately prepare for periodic tests, which gets the students to be more involved thereby enhancing their performance.

\subsection{Continuity with Previous Research}

The authors' previous works (e.g. Dömeová et al., 2011; Vostrá-Vydrová et al., 2012; Jindrová et al., 2013; Dömeová et al., 2013) deal with some courses in the University of Life Sciences in Prague. These studies were based on a self-evaluation of the students expressed in a questionnaire. Present study is based only on objective 
information on the students' results made by the teachers.

\subsection{Goal of Present Investigation}

The study is mapping the students' progress throughout the whole course requirements using the Markov chain approach. The goal is to make clear how the various stages of the course requirements (partial evaluations) contribute to the final exam. The Markov chain approach is based on the fact that the student is allowed to continue only when completing the previous duty.

\section{Method}

In the following section, the means of computation are described as well as the characteristics of the data used in the model. It is also necessary to briefly describe the process of examination and the conditions of successful completion of the course. Students' advance throughout the course of Mathematical Methods in Economics II is depicted here in two stages. The first stage shows students' progress through the exam terms they have available during the exam period. The second stage illustrates how the progress is made within the single exam term as each exam term consists of number of stages that have to be passed (e.g. writing part, oral part). The general idea of modelling here is considering the various stages of the examination process to be the following states of a Markov chain. It is then possible to determine the probability of students' success at the exam as well as the mean time taken to successful exam completion.

\subsection{Computational Background}

The computation itself is based on theory of Absorbing Markov chain. This is a special case of Markov chain with the finite state(s). The basics of Markov chain theory will not be described here as it is quite well-known topic. To find more about its fundamentals see for example Tijms (2003), Borovkov (2003) or Grinstead and Snell (1997). We shall further use the notation introduced by Grinstead and Snell (1997). Let us define the transition matrix $\boldsymbol{P}$ of the Markov Chain with $r$ absorbing states and $t$ transient states:

$$
P=\left(\begin{array}{cc}
Q & R \\
0 & I
\end{array}\right)
$$

where $Q$ is $t \times t$ matrix expressing transitions between transient states, $R$ is nonzero $t \times r$ matrix expressing transitions from transient states to absorbing states, 0 is the $r \times t$ zero matrix and $I$ is $r \times r$ identity matrix. The transition matrix is filled with the normalized gathered data (i.e. frequencies of students in the particular state). The computation is done using fundamental matrix $\boldsymbol{N}$ given as

$$
N=(I-Q)^{-1}
$$

The matrix $I$ here in formula (2) is of size $t \times t$ and thus generally different from the matrix $I$ from (1). Elements of the matrix $\boldsymbol{N}$ express how many times the Markov process in average reaches the transient states. With the fundamental matrix $\boldsymbol{N}$ it is possible to define the expected number of steps before the chain is absorbed. For each transient state the number of steps can be expressed as $i-t h$ component of column vector $t:$

$$
t=N . c
$$

where $c$ is a column vector of length $t$ all of whose components are equal 1 . The fundamental matrix $N$ is also useful for computation of absorbing probabilities. Let $b_{i j}$ be the probability that the absorbing chain will be absorbed in an absorbing state $j$ when it started from transient state $i$. Let $\boldsymbol{B}$ be the matrix with components $b_{i j}$. Then $\boldsymbol{B}$ is an $t \times r$ matrix defined as

$$
B=N R
$$

where $\boldsymbol{N}$ is the fundamental matrix and $\boldsymbol{R}$ is the sub-matrix from the transition matrix $\boldsymbol{P}$ above.

\subsection{The Course and the Exam}

Mathematical methods in economics II is taught in the $3^{\text {rd }}$ semester of the bachelor studies. The course consists of some advanced methods in the field of operations research, such as Game theory, Decision Making, Inventory control etc. The course falls under the general rules applied in the Czech University of Life Sciences. That is, every student has to receive the credit first, regarding his activity during the semester as well as the successful completion of the credit test(s). After the credit has been received it is possible to take an exam. In case of failure 
there is an option to repeat the exam twice (if possible due to exam term capacity). If any student fails to succeed even at the $3^{\text {rd }}$ exam term he has to try again in the next year. This is, however, not taken into consideration in our computations.

During the semester, the students are required to take a number of small credit tests. 660 points out of 1100 are required to receive the credit at the end. For those students particularly good there is an option to receive so called bonus points that can be useful at the exam later. Practically, for every ten points above 900 , the student will receive 1 bonus point (so 20 at max) that is added to the writing exam result later, possibly making it easier to pass.

The exam itself consists of few stages that have to be gone through before it is successfully passed. After the student has received the credit he comes to an exam term. The exam starts with the writing part. One can get maximum 100 points out of the test (or possibly 120 with the bonus points). The test is divided into two sections-the theory ( 40 points) and practice (60 points). There is a requirement for passing the writing part-at least 20 points from the practical part. The number of points achieved from both parts will affect the exam final result. There is the rule that the students have to reach over 50 points to get to the oral part of the exam. Those who have not reached over the limit fail the exam. The achieved points generally affect the final result of the entire exam that can be Excellent, Very Good, Good, or Failed. The number of points corresponds directly with the final result as shown in the Table 1 . Although it can be changed slightly during the oral part of the exam depending if the student was able - and in what manner-to answer the questions of the teacher.

Table 1. Final result depending on the points achieved from the test

\begin{tabular}{ll}
\hline Writing test points & Final result \\
\hline $0-50$ & Failed \\
$51-60$ & Failed-allowed to try to improve at the oral exam \\
$61-75$ & Good \\
$76-90$ & Very good \\
$91-100(120)$ & Excellent \\
\hline
\end{tabular}

Note that if the student gains 51-60 points from the test he is allowed to convince the teacher of his knowledge at the oral exam and possibly improve the final result to Good (or rarely even better). Similarly if the student receives more than 60 points from the test and does not prove the sufficient knowledge at the oral exam he can fail anyway.

\subsection{Participants and Data Gathering}

There is a Student information system in CULS in which the grades are filled in by the teacher after the exam. It is rather simple to export all the results to excel file that gives a lot of possibilities to work with. For each student, it is possible to see how many attempts he needed to pass (if so) the exam. This makes available all data required for modelling of the first stage of the experiment. The data for the second stage cannot be found in the system. There is but a final result and number of attempts, however, there is no information how many points the particular student gained from the writing test and how many bonus points (if any) he had brought to the exam. For the first stage, the data of all students attending the course are used. There are total of 998 students. For the second stage, it was necessary to gather data manually. It was not possible to gather results for all 998 students due to technical reasons. Finally 278 students were observed in terms of the results of both writing and oral exams.

\subsection{Case Study}

The case study consists of two stages. The first shows the students' progress through all exam terms during the exam period and the second shows students' progress through single exam term more in detail, both of them with the help of Markov chains.

\subsubsection{First Stage}

There are 998 students that enrolled the course of Mathematical methods in economics II. Let us define four absorbing states and four transient states of the Markov chain. The absorbing states are Failed, Successful at $1^{\text {st }}$ attempt, Successful at $2^{\text {nd }}$ attempt, Successful at $3^{\text {rd }}$ attempt. Once one of these absorbing states is reached it 
cannot be left anymore. The transient states are Course enrolled, Credit acquired, Failed at the $1^{\text {st }}$ attempt, Failed at the $2^{\text {nd }}$ attempt. It is possible to create matrix of frequencies with all eight states. For better convenience the matrix is depicted as the Table 2.

Table 2. Matrix of frequencies-stage 1

\begin{tabular}{|c|c|c|c|c|c|c|c|c|c|}
\hline & & \multicolumn{4}{|c|}{ Transient states } & \multicolumn{4}{|c|}{ Absorbing states } \\
\hline & & $\begin{array}{c}\text { Course } \\
\text { enrolled }\end{array}$ & $\begin{array}{c}\text { Credit } \\
\text { acquired }\end{array}$ & $\begin{array}{l}\text { Failed at } \\
1^{\text {st }} \text { attempt }\end{array}$ & $\begin{array}{l}\text { Failed at } \\
2^{\text {nd }} \\
\text { attempt }\end{array}$ & Failed & $\begin{array}{c}\text { Successful at } \\
1^{\text {st }} \text { attempt }\end{array}$ & $\begin{array}{l}\text { Successful at } \\
2^{\text {nd }} \text { attempt }\end{array}$ & $\begin{array}{c}\text { Successful at } \\
3^{\text {rd }} \text { attempt }\end{array}$ \\
\hline \multirow{4}{*}{$\begin{array}{c}\text { Transient } \\
\text { states }\end{array}$} & $\begin{array}{l}\text { Course } \\
\text { enrolled }\end{array}$ & 0 & 979 & 0 & 0 & 19 & 0 & 0 & 0 \\
\hline & $\begin{array}{c}\text { Credit } \\
\text { acquired }\end{array}$ & 0 & 0 & 431 & 0 & 0 & 548 & 0 & 0 \\
\hline & $\begin{array}{c}\text { Failed at } 1^{\text {st }} \\
\text { attempt }\end{array}$ & 0 & 0 & 0 & 110 & 201 & 0 & 120 & 0 \\
\hline & $\begin{array}{c}\text { Failed at } 2^{\text {nd }} \\
\text { attempt }\end{array}$ & 0 & 0 & 0 & 0 & 92 & 0 & 0 & 18 \\
\hline \multirow{4}{*}{$\begin{array}{c}\text { Absorbing } \\
\text { states }\end{array}$} & Failed & 0 & 0 & 0 & 0 & 312 & 0 & 0 & 0 \\
\hline & $\begin{array}{l}\text { Successful at } \\
1^{\text {st }} \text { attempt }\end{array}$ & 0 & 0 & 0 & 0 & 0 & 548 & 0 & 0 \\
\hline & $\begin{array}{l}\text { Successful at } \\
2^{\text {nd }} \text { attempt }\end{array}$ & 0 & 0 & 0 & 0 & 0 & 0 & 120 & 0 \\
\hline & $\begin{array}{c}\text { Successful at } \\
3^{\text {rd }} \text { attempt }\end{array}$ & 0 & 0 & 0 & 0 & 0 & 0 & 0 & 18 \\
\hline
\end{tabular}

The numbers in the table show how many students moved from one state to another. The rows indicate states (experiment $n-1$ ) preceding the states (experiment $n$ ) in the columns. For example, in the $1^{\text {st }}$ row, number 979 means the number of students who enrolled the course and managed to gain the credit. Number 19 indicates the number of students who failed to gain the credit. Obviously, there is no possibility to move from absorbing state to transient state (lower-left sub-matrix). Reaching the absorbing state is terminal as shown in the lower-right sub-matrix. Sum of its diagonal numbers is naturally the same as the entering number of students, i.e. 998.

For the purpose of computation, the transition matrix of Markov chain is required. The transition matrix, however, works with probabilities and not with frequencies as we have them in the Table 2. It is necessary to transform the matrix of frequencies (Table 2) into the proper transition matrix. This can be done easily by normalizing each row of the matrix by

$$
p_{i j}=\frac{f_{i j}}{\sum_{j} f_{i j}}
$$

where $f_{i j}$ acts as an element of the frequency matrix (Table 2) and $p_{i j}$ is an element of the transition matrix. It is then possible to apply the formulae (2), (3) and (4).

\subsubsection{Second Stage}

278 students were observed closely in terms of their progress through single exam term of Mathematical methods in economics II. Once again, let us define four absorbing states and four transient states of the Markov chain. The absorbing states are Failed, Good, Very good, Excellent. The transient states are Exam enrolled, Practical part successfully finished, Entire test finished (50-59 points), Entire test finished (60-100/120 points). Two groups of students were observed separately depending whether they have some bonus points (175 students) or not (103 students). For both groups, the frequency matrices are created as Tables 3 and 4. 
Table 3. Matrix of frequencies-stage 2-students without bonus points

\begin{tabular}{|c|c|c|c|c|c|c|c|c|c|}
\hline \multirow{2}{*}{\multicolumn{2}{|c|}{$\begin{array}{c}\text { Students without bonus } \\
\text { points }\end{array}$}} & \multicolumn{4}{|c|}{ Transient states } & \multicolumn{4}{|c|}{ Absorbing states } \\
\hline & & \multirow{2}{*}{$\begin{array}{c}\begin{array}{c}\text { Exam } \\
\text { enrolled }\end{array} \\
0\end{array}$} & \multirow{2}{*}{$\begin{array}{c}\text { Practical part } \\
\text { successfully } \\
\text { finished }\end{array}$} & \multirow{2}{*}{$\begin{array}{c}\text { Entire test } \\
\text { finished } \\
(50-59) \\
\text { points } \\
0\end{array}$} & \multirow{2}{*}{$\begin{array}{c}\text { Entire test } \\
\text { finished } \\
(60-100) \\
\text { points } \\
0\end{array}$} & \multirow{2}{*}{$\begin{array}{c}\text { Failed } \\
29\end{array}$} & \multirow{2}{*}{$\begin{array}{c}\text { Good } \\
0\end{array}$} & \multirow{2}{*}{$\begin{array}{c}\text { Very } \\
\text { good }\end{array}$} & \multirow{2}{*}{$\begin{array}{c}\text { Excellent } \\
0\end{array}$} \\
\hline \multirow{4}{*}{$\begin{array}{c}\text { Transient } \\
\text { states }\end{array}$} & $\begin{array}{c}\text { Exam } \\
\text { enrolled }\end{array}$ & & & & & & & & \\
\hline & $\begin{array}{l}\text { Practical part } \\
\text { successfully } \\
\text { finished }\end{array}$ & 0 & 0 & 23 & 26 & 25 & 0 & 0 & 0 \\
\hline & $\begin{array}{l}\text { Entire test } \\
\text { finished } \\
(50-59) \text { points }\end{array}$ & 0 & 0 & 0 & 0 & 6 & 13 & 3 & 1 \\
\hline & $\begin{array}{c}\text { Entire test } \\
\text { finished } \\
(60-100) \\
\text { points }\end{array}$ & 0 & 0 & 0 & 0 & 3 & 9 & 9 & 5 \\
\hline \multirow{4}{*}{$\begin{array}{l}\text { Absorbing } \\
\text { states }\end{array}$} & Failed & 0 & 0 & 0 & 0 & 63 & 0 & 0 & 0 \\
\hline & Good & 0 & 0 & 0 & 0 & 0 & 22 & 0 & 0 \\
\hline & Very good & 0 & 0 & 0 & 0 & 0 & 0 & 12 & 0 \\
\hline & Excellent & 0 & 0 & 0 & 0 & 0 & 0 & 0 & 6 \\
\hline
\end{tabular}

Table 4. Matrix of frequencies-stage $2-$ students with bonus points

\begin{tabular}{|c|c|c|c|c|c|c|c|c|c|}
\hline \multirow{2}{*}{\multicolumn{2}{|c|}{ Students with bonus points }} & \multicolumn{4}{|c|}{ Transient states } & \multicolumn{4}{|c|}{ Absorbing states } \\
\hline & & $\begin{array}{c}\text { Exam } \\
\text { enrolled }\end{array}$ & $\begin{array}{l}\text { Practical part } \\
\text { successfully } \\
\text { finished }\end{array}$ & $\begin{array}{l}\text { Entire test } \\
\text { finished } \\
(50-59) \\
\text { points }\end{array}$ & \multirow{2}{*}{$\begin{array}{c}\text { Entire test } \\
\text { finished } \\
(60-120) \\
\text { points } \\
0\end{array}$} & \multirow{2}{*}{$\begin{array}{c}\text { Failed } \\
32\end{array}$} & \multirow{2}{*}{$\begin{array}{c}\text { Good } \\
0\end{array}$} & \multirow{2}{*}{$\begin{array}{c}\text { Very } \\
\text { good }\end{array}$} & \multirow{2}{*}{$\begin{array}{c}\text { Excellent } \\
0\end{array}$} \\
\hline \multirow{4}{*}{$\begin{array}{c}\text { Transient } \\
\text { states }\end{array}$} & $\begin{array}{c}\text { Exam } \\
\text { enrolled }\end{array}$ & 0 & 143 & 0 & & & & & \\
\hline & $\begin{array}{l}\text { Practical part } \\
\text { successfully } \\
\text { finished }\end{array}$ & 0 & 0 & 14 & 125 & 4 & 0 & 0 & 0 \\
\hline & $\begin{array}{l}\text { Entire test } \\
\text { finished } \\
(50-59) \text { points }\end{array}$ & 0 & 0 & 0 & 0 & 3 & 11 & 0 & 0 \\
\hline & $\begin{array}{c}\text { Entire test } \\
\text { finished } \\
(60-120) \\
\text { points }\end{array}$ & 0 & 0 & 0 & 0 & 13 & 51 & 33 & 28 \\
\hline \multirow{4}{*}{$\begin{array}{c}\text { Absorbing } \\
\text { states }\end{array}$} & Failed & 0 & 0 & 0 & 0 & 52 & 0 & 0 & 0 \\
\hline & Good & 0 & 0 & 0 & 0 & 0 & 62 & 0 & 0 \\
\hline & Very good & 0 & 0 & 0 & 0 & 0 & 0 & 33 & 0 \\
\hline & Excellent & 0 & 0 & 0 & 0 & 0 & 0 & 0 & 28 \\
\hline
\end{tabular}

The interpretation of these frequency tables (matrices) is similar to the one under the Table 2. Once again, it is necessary to transform the frequency matrices into proper transition matrices which are done by (5). 


\section{Results}

Two stages of students' progress through the course and exam were observed with the help of Markov chains. Applying the formulae (2), (3) and (4), it is possible to determine number of steps before the chain is absorbed as well as the probabilities of absorbing. The results for the first stage can be found in the Table 5 .

Table 5. Results of the first stage

\begin{tabular}{cccccc}
\hline & Failed & $\begin{array}{c}\text { Successful at } 1^{\text {st }} \\
\text { attempt }\end{array}$ & $\begin{array}{c}\text { Successful at 2 } \\
\text { attempt }\end{array}$ & $\begin{array}{c}\text { Successful at } 3^{\text {rd }} \\
\text { attempt }\end{array}$ & $\begin{array}{c}\text { Expected number of steps } \\
\text { before absorption }\end{array}$ \\
\hline $\begin{array}{c}\text { Course } \\
\text { enrolled }\end{array}$ & 0.31 & 0.55 & 0.12 & 0.02 & 2.52 \\
$\begin{array}{c}\text { Credit acquired } \\
\text { Failed at 1 } \\
\text { attempt }\end{array}$ & 0.3 & 0.56 & 0.12 & 0.02 & 0.04 \\
$\begin{array}{c}\text { Failed at 2 } \\
\text { attempt }\end{array}$ & 0.84 & 0 & 0.28 & 0.16 & 1.55 \\
\hline
\end{tabular}

The interpretation of the Table 5 is as follows. The rows indicate transient states and columns indicate absorbing states. The values inside the table show the probability of transition from transient state to absorbing state. For example student who enrolled the course has a "chance" to fail at the end with the probability of 0.31 . The last column on the right shows how many transitions are expected to reach any absorbing state. Obviously, at the beginning (state Course enrolled) the expected number of steps is the highest.

The second stage of the observation was divided into two sub-sections depending on whether the students had bonus points or not. Results for the students without bonus points are shown first at the Table 6 .

Table 6. Results of the second stage-students without bonus points

\begin{tabular}{cccccc}
\hline & Failed & Good & Very good & Excellent & Expected number of steps before absorption \\
\hline Exam enrolled & 0.61 & 0.21 & 0.12 & 0.06 & 2.19 \\
Practical part successfully finished & 0.46 & 0.30 & 0.16 & 0.08 & 1.66 \\
Entire test finished (50-59) points & 0.26 & 0.57 & 0.13 & 0.04 & 1 \\
Entire test finished (60-100) points & 0.11 & 0.35 & 0.35 & 0.19 & 1 \\
\hline
\end{tabular}

One can interpret the table as the students' chance of getting one of the four grades. For example, probability of getting excellent grade at the beginning of the exam is 0.06 .

Second, the same situation is shown for the students who brought some bonus points to the exam thanks to their effort in the semester. The probabilities and number of expected transitions are shown in the Table 7.

Table 7. Results of the second stage-students with bonus points

\begin{tabular}{cccccc}
\hline & Failed & Good & Very good & Excellent & Expected number of steps before absorption \\
\hline Exam enrolled & 0.3 & 0.35 & 0.19 & 0.16 & 2.61 \\
Practical part successfully finished & 0.14 & 0.43 & 0.23 & 0.2 & 1.97 \\
Entire test finished (50-59) points & 0.21 & 0.79 & 0 & 0 & 1 \\
Entire test finished (60-120) points & 0.1 & 0.41 & 0.26 & 0.23 & 1 \\
\hline
\end{tabular}




\section{Discussion}

Let us focus first at the results of first stage of the experiment depicting students' progress throughout the whole exam period. At the beginning (state course enrolled), the probability of the failure (meaning that student will not succeed at any term) for a student is 0.31 and the success 0.69 . A student is most likely to succeed at the first attempt with the probability of 0.55 . Being in the state credit acquired does not make much of a change compared to the state course enrolled. There were only 19 students who failed to acquire the credit. Considering the total number of students observed, the number of 19 is insignificant. In other words, reaching for the credit does not make a significant change in probability of the course completion. If one has failed at the first attempt the probability of the repeated failure is 0.68 . If one has failed at the second attempt the probability of the failure is even higher 0.84. That shows the fact that there is rather low improvement of those students who failed at their first attempt. Students who come and fail the exam repeatedly are usually those who do not have enough predispositions to master required knowledge at all.

The results suggest that only one attempt will show the student's ability of passing or failing the exam but the evaluation in several steps is giving out an important feedback which is able to change the final results. By Yeh, 2009 , the feedback builds students' self-esteem, confidence and desire to perform at a high level, then lack of adequate feedback is perhaps the most important cause of low student achievement.

There is but a small proportion of students who had failed at the first attempt and then succeeded at the second or third. Those are the students who underestimated their preparation for the exam or students who simply had "bad luck" at the first attempt though they might have the ability and knowledge to succeed otherwise. It is necessary to bear in mind some random and unmeasured factors including the student's possible health or other problems (Grant, 2007). More attempts can eliminate the current indisposition and other random factors which can affect the final result if there only one personal contact with the teacher.

At the beginning, the expected number of steps (moves from one state to another) is 2.52 in average. Of course, with the increasing number of steps taken, the number of expected steps before absorption lowers. If one is in the state at Failed 2nd attempt the expected number of remaining steps is obviously 1 as there is no other option of more steps to be taken.

\subsection{Progress throughout the Exam Procedure}

The second stage of the experiment was related to students' progress throughout the single exam term regardless the number of attempts.

\subsubsection{Students without Bonus Points}

Before the test starts, there is 0.61 probability of failure and 0.39 of success. Before the beginning of the exam there is very low chance to receive the best grade excellent. After the practical part of the exam is finished, students' probability to succeed raises to 0.54 . At this point, the most decisive and important part is still ahead of the students. Students who finished their test with the "critical" result 50-59 points have 0.74 probability of getting any grade; those with more points from the test have even greater probability of succession 0.89 . Students with 50-59 points gained have lower chance to be successful because as the teacher is more thorough with asking questions. There is also 0.11 probability to fail even with the more than 59 points gained. These students are usually those poorly prepared, writing test cheaters or sometimes students who are over-nervous but otherwise well prepared.

\subsubsection{Students with Bonus Points}

One can notice significantly better results in this category. At the beginning, students have only 0.3 probability of failure. Once the practical part is done the probability of failure lowers to 0.14 . With the test finished with $50-59$ points probability of success is 0.79 and with the more than 60 points gained it is even 0.9 .

It is clear that the students with bonus points from the semester, i.e. those working better continuously, have better chance to pass the exam. There are no big differences between these two groups of students in the probability to fail the exam after being successful in the examination test: compare the values (Tables 6 and 7 , lower lines) 0.1 and 0.11 . It proposes that the students who are able to write the test with satisfactory number of points can pass the exam without the bonus points. It can be concluded that the partial evaluation during the semester is more helpful to the weaker students what is an inverse effect comparing with the higher grading standards (Figlio \& Lucas, 2004).

The effect of changing the grading standards is ambiguous. More able students may increase effort in order to reach the new standard while less able students, who must increase effort by a greater amount to increase their 
achievement, may give up instead (Betts \& Grogger, 2003). On the other hand the grade inflation defined as "student attainment of higher grades independent of increased levels of academic attainment" (Eiszler, 2002) can have very negative effect to the knowledge acquired during the studies. According to Oleinik, 2009, the best remedy against grade inflation would be evaluations, both of students and of instructors, in a stable set of exogenous norms, academic independence and fight against corruption.

Another factor which can help the low-ability students is an introduction of both effort and knowledge grades. Swinton, 2010, finds that the effort grade affects the knowledge grade positively because more student effort does lead to increase learning.

The further research should be focused on more detailed analyses of dropouts, and on comparison of high-ability and low-ability students. It might be useful to introduce some effort evaluation, e.g. number of hours spent on studying, number of self-tests taken, etc., and assesses the improvement of knowledge, dropout level, and the final grades. The particular items difficulty should be possibly analyzed by an independent study.

\section{Acknowledgments}

This paper was created under the project 20121055, with the support of Internal Grant Agency, Czech University of Life Sciences.

\section{References}

Ajogbeje, O. J., Ojo, A. A., \& Ojo, O. A. (2013). Effect of Formative Testing with Feedback on Students' Achievement in Junior Secondary School Mathematics in Ondo State Nigeria. International Education Research, 1(2), 8-20.

Awan, R. N., Ghazala, N., \& Anjum, N. (2011). A Study of Relationship between Achievement Motivation, Academic Self Concept and Achievement in English and Mathematics at Secondary Level. International Education Studies, 4(3), 72-79.

Beleche, T., David, F., \& Marks, M. (2012). Do course evaluations truly reflect student learning? Evidence from an objectively graded post-test. Economics of Education Review, 31(5), 709-719.

Betts, J., \& Grogger, J. (2003).The impact of grading standards on student achievement, educational attainment, and entry-level earnings. Economics of Education Review, 22(4), 343-352.

Borovkov, K. (2003). Elements of Stochastic Modelliing. Singapore: World Scientifici Publishing Co. Pte. Ltd.

Broadfoot, P., \& Black, P. (2004). Redefining assessment? The first ten years of Assessment in Education. Assessment in Education, 11(1), 7-27.

Christoforidou, M., Kyriakides, L., Antoniou, P., \& Creemers, B. P. M. (2014). Searching for stages of teacher's skills in assessment. Studies in Educational Evaluation, 40, 1-11.

De Witte, K., Cabus, S., Thyssen, G., Groot, W., \& van den Brink, H. (2013). A critical review of the literature on school dropout. Educational Research Review, 10, 13-28.

Dean, R. D., \& DeCicca, P. P. (2001). Higher standards, more dropouts? Evidence within and across time.Economics of Education Review, 20(5), 459-473. http://dx.doi.org/10.1016/S0272-7757(00)00022-4

DeBrew, J. K., \& Lewallen, L. P. (2014). To pass or fail? Understanding the factors considered by faculty in the clinical evaluation of nursing students. Nurse Education Today, 34(3), 631-636.

Dochy, F., Segers, M., \& Buehl, M. (1999). The relation between assessment practices and outcomes of studies: The case of research on prior knowledge. Review of Educational Research, 69(2), 147-188.

Dömeová, L., \& Jindrová, A. (2013). Unethical Behaviour of the Students of the Czech University of Life Sciences. International Education Studies, 6(11), 79-86.

Dömeová, L., Vydrová, H., \& Jindrová, A. (2011). Comparison of Full Time and Combined Studies with Gender Aspect. Journal on Efficiency and Responsibility in Education and Science, 4(1), 31-45.

Eiszler, C. F. (2002). College students' evaluations of teaching and grade inflation. Research in Higher Education, 4(4), 483-501.

Figlio, D., \& Lucas, M. (2004). Do high grading standards affect student performance? Journal of Public Economics, 88(9, 10), 1815-1834. http://dx.doi.org/10.1016/S0047-2727(03)00039-2

Grant, D. (2007). Grades as information. Economics of Education Review, 26(2), 201-214.

Grinstead, C. M., \& Snell, J. L. (1997). Introduction to probability. Providence, RI: American Mathematical 
Society.

Hamid, M. H. S., Shahrill, M., Matzin, R., Mahalle, S., \& Mundia, L. (2013). Barriers to Mathematics Achievement in Brunei Secondary School Students: Insights into the Roles of Mathematics Anxiety, Self-Esteem, Proactive Coping, and Test Stress. International Education Studies, 6(11), 39-46.

Jindrová, A., Vostrá-Vydrová, H., \& Dömeová, L. (2013). The students' evaluation of the e-support in the full time form of study. Journal on Efficiency and Responsibility in Education and Science, 6(2), 119-133.

Kyriakides, L., Creemers, B. P. M., \& Antoniou, P. (2009). Teacher behaviour and student outcomes: Suggestions for research on teacher training and professional development. Teaching and Teacher Education, 25(1), $12-23$.

Oleinik, A. (2009). Does education corrupt? Theories of grade inflation. Educational Research Review, 4(2), 156-164. http://dx.doi.org/10.1016/j.edurev.2009.03.001

Scanlan, J. M., Care, W. D., \& Gessler, S. (2001). Dealing with the unsafe student in clinical practice. Nurse Educator, 26(1), 23-27.

Stratton, R., Myers, S., \& King, R. (1994). Faculty behavior, grades, and student evaluations. Journal of Economic Education, 25(1), 5-15.

Swinton, O. H. (2010). The effect of efford grading on learning. Economicsof Education Review, 29(6), 1176-1182. http://dx.doi.org/10.1016/j.econedurev.2010.06.014

Tijms, H. C. (2003). A First Course in Stochastic Models. Chichester: Wiley.

Van de Watering, G., \& van der Rijt, J. (2006). Teachers' and students' perceptions of assessments: A review and a study into the ability and accuracy of estimating the difficulty levels of assessment items. Educational Research Review, 1(2), 133-147. http://dx.doi.org/10.1016/j.edurev.2006.05.001

Vostrá-Vydrová, H., Jindrová, A., \& Dömeová, L. (2012). Evaluation of Results in Chosen Subjects and Analysis of the Motivation of Adult Students. Journal on Efficiency and Responsibility in Education and Science, $5(1), 36-45$.

Yeh, S. S. (2009). Shifting the bell curve: The benefits and costs of raising student achievement. Evaluation and Program Planning, 32(1), 74-82. http://dx.doi.org/10.1016/j.evalprogplan.2008.08.006

\section{Copyrights}

Copyright for this article is retained by the author(s), with first publication rights granted to the journal.

This is an open-access article distributed under the terms and conditions of the Creative Commons Attribution license (http://creativecommons.org/licenses/by/3.0/). 